\title{
Marie-Antoinette. Anthologie et dictionnaire
}

\section{Annie Duprat}

\section{(2) OpenEdition}

\section{Journals}

Édition électronique

URL : https://journals.openedition.org/ahrf/8703

DOI : 10.4000/ahrf.8703

ISSN : 1952-403X

\section{Éditeur :}

Armand Colin, Société des études robespierristes

\section{Édition imprimée}

Date de publication : 1 mars 2007

Pagination : 183-185

ISSN : 0003-4436

\section{Référence électronique}

Annie Duprat, « Marie-Antoinette. Anthologie et dictionnaire », Annales historiques de la Révolution

française [En ligne], 347 | janvier-mars 2007, mis en ligne le 21 juillet 2008, consulté le 24 avril 2022. URL : http://journals.openedition.org/ahrf/8703 ; DOI : https://doi.org/10.4000/ahrf.8703

Ce document a été généré automatiquement le 24 avril 2022.

Tous droits réservés 


\title{
Marie-Antoinette. Anthologie et dictionnaire
}

\author{
Annie Duprat
}

\section{RÉFÉRENCE}

Catriona Seth, Marie-Antoinette. Anthologie et dictionnaire, Paris, Robert Laffont, coll. Bouquins, 960 p., ISBN 2-221-10583-4, $29 €$.

1 Écrit par une spécialiste de littérature du XVIII ${ }^{\mathrm{e}}$ siècle, ce livre se présente comme une somme sur ce que l'on pourrait à présent nommer "l'épopée de la dernière reine de France ». À la différence de la plupart des publications suscitées, de près ou de loin, par l'actualité cinématographique de l'année 2006 (dont il est question par ailleurs dans le présent numéro des Annales historiques de la Révolution française), il se caractérise par un souci d'information et une rigueur scientifique exemplaires. Le parti-pris éditorial d'une pareille « anthologie » associée ici à un "dictionnaire » était pourtant risqué, en raison de l'importance d'un sujet qui a fait couler autant d'encre depuis autant d'années et qui ne cesse de départager les nostalgiques d'une monarchie à bien des égards fantasmée, d'une part, ou d'une Révolution héroïque et purificatrice, d'autre part. Le genre de l'anthologie est un classique des lettres françaises qui suppose un choix de l'auteur, personnel certes, mais qu'il faut justifier par l'hypothèse de travail qui le fonde. L'ouvrage est organisé en six chapitres suivis d'un dictionnaire d'environ 120 pages, d'une brève bibliographie et d'un très long index (une trentaine de pages). L'économie générale du livre répond donc au choix de Catriona Seth qui, après avoir procédé à un résumé sensible et brillant de la personnalité d'une reine dont elle cherche "les mille visages", regroupe les textes qu'elle a choisis en six rubriques ("Madame ma très chère mère ", "Regards sur une souveraine ", "La reine en procès ", « Historiens et mémorialistes ", "Hommes de lettres » et « Marie-Antoinette face à l'historiographie moderne ", un tour d'horizon rapide des historiennes du " gender »). Les chapitres n'ont pas été regroupés selon un classement thématique des sources, ce qui aurait eu le mérite de la clarté pour le lecteur en lui montrant les 
différents registres des discours tenus sur Marie-Antoinette (des pamphlets aux biographies, des correspondances avec Marie-Thérèse d'Autriche aux extraits des minutes du procès d'octobre 1793 , les textes collationnés sont d'origine, de date et de nature très diverses). L'auteur n'a pas non plus choisi un regroupement chronologique, même si elle y parvient, semble-t-il, dans le classement des trois derniers chapitres. Ce choix personnel, qui n'est justifié à aucun moment du livre, peut être critiqué; pourtant, il doit être accepté ici puisqu'il correspond justement à la liberté que donne le genre de l'anthologie. La "Toinettomania" actuelle amoindrit l'importance de quelques-uns des textes publiés ici puisqu'ils viennent tout juste d'être réédités (on pense à la collection «Le temps retrouvé » du Mercure de France pour le Mémoire écrit par Marie-Thérèse Charlotte de France, ou pour les Mémoires de la baronne d'Oberkirch, déjà accessibles sur le site Gallica de la BNF ou encore pour les Actes du Tribunal révolutionnaire compilés par Gérard Walter et récemment réimprimés). Parmi les choix des écrits retenus pour cette anthologie, on notera la place importante accordée à l'Histoire de Marie-Antoinette des frères Goncourt (édition de 1858), souvent aveugle dans ses jugements (en particulier lorsqu'ils minorent le rôle politique de la reine), citée inextenso tout comme le bref Dies Irae de Léon Bloy, très hagiographique, au sens propre, puisqu'on peut y lire : «Marie-Antoinette a fait comme saint Denys. Elle a ramassé sa tête coupée et elle s'est mise à marcher et à régner toute seule, cette tête à la main. Règne durable, celui-là, que ne pourront désormais abolir ni les émeutes, ni les échafauds, ni les fusillades, ni les mitraillades, ni les incendies des capitales ». Bien que Léon Bloy y assure à chaque paragraphe qu'elle n'était pas une sainte, il transforme la reine guillotinée en une parfaite martyre chrétienne. L'étrange Mascarade à Trianon (1845) d'Arsène Houssaye est un bijou qui conjugue l'esprit des saynètes bucoliques si en vogue au XVIII ${ }^{\mathrm{e}}$ siècle avec de fausses prophéties (il faut lire la description de Louis XVI évoquant l'invention de « la civilité de la mort » par monsieur Guillotin en se caressant le cou !) et une invocation de Jean-Jacques Rousseau encore plus improbable...

2 Pourtant, si l'on reprend les notices liminaires de chacun des documents reproduits, on est parfois mal à l'aise en raison du flou de l'appareil critique d'un travail qui a pourtant été établi de manière scientifique. Ce sentiment apparaît surtout à la lecture de la correspondance échangée entre Marie-Antoinette et sa mère; Catriona Seth publie les 95 lettres recopiées sur les originaux conservés aux Archives d'État à Vienne, en leur adjoignant des notes scientifiques qui s'appuient sur l'édition d'Arneth et Geffroy (Correspondance secrète entre Marie-Thérèse et le comte de Mercy-Argentau, avec les lettres de Marie-Thérèse et de Marie-Antoinette, Paris, Firmin-Didot, 1874). À aucun moment, elle ne fait mention de la récente édition par Évelyne Lever de cette correspondance (Marie-Antoinette, Correspondance (1770-1793), Paris, Tallandier, 2005). On pourrait supposer qu'elle n'a pas eu connaissance de ce dernier livre, sorti en librairie en septembre 2005, juste une année avant la présente anthologie; pourtant, plusieurs notices du " Dictionnaire ", dont celle consacrée spécialement à Sofia Coppola à l'occasion de la réalisation de son film Marie-Antoinette (p. 732) montrent que la rédaction du présent ouvrage s'est poursuivie durant le printemps 2006. Cette remarque n'est pas un détail car il aurait été intéressant de comparer ces 95 lettres collationnées sans censure avec l'édition du XIX ${ }^{e}$ siècle qui faisait autorité jusqu'à présent. Nous avons eu l'occasion de montrer que des coupures intempestives pratiquées par Arneth et Geffroy avaient pu modifier nos connaissances, en particulier dans la lettre de la reine du 14 janvier 1776 sur la soi-disant opération du roi (voir Une reine brisée, p. 98); cette erreur persiste encore largement dans la presse et l'édition 
grand public. La présente édition des 95 lettres échangées entre Marie-Antoinette et sa mère est tout à fait bienvenue car elle est assortie de notes bien supérieures en nombre et en qualité à celles de l'édition d'Évelyne Lever (y figure également une très brève missive datée du 7 juillet 1778 dans laquelle la reine indique la date prévue de son accouchement, oubliée dans l'édition de Lever).

Cependant, si le livre est orné de quelques images, elles ne sont pas ou mal référencées (il n'y a pas de table des illustrations, la gravure Un peuple est sans honneur page 144 est donnée, à la suite de Chantal Thomas, comme étant le frontispice des Crimes des reines de France, de Louise de Kéralio, 1791; or, nous avons montré - L'événement, histoire, représentation, mémoire, Créaphis, 2003 - que cette estampe, qui figure dans la collection De Vinck de la BNF au numéro 1134, a été produite à l'occasion de l'affaire du collier, en 1785). Enfin, pour en terminer avec la critique, notons l'absence de prise en compte d'un article de Véronique Campion-Vincent et Véronique Kawan Shojaei, «MarieAntoinette et son célèbre dire », publié dans la présente revue et cité dans la bibliographie alors que l'inévitable notice du « Dictionnaire » ne tient aucun compte de ses conclusions. Il est vrai que le livre d'Antonia Fraser, si auréolé de gloire médiatique, contribue à perpétuer un questionnement que l'on aurait aimé croire définitivement clos. 